\title{
Study an Fertilizer Effect of Wheat in Dryland Area of Eastern Gansu Province, China
}

\author{
Shi Jubao ${ }^{1}$, Lei Zongchang ${ }^{1}$, Shi Shuping ${ }^{2,}$ * \\ ${ }^{1}$ Gansu Province Agricultural Technology Promotion Center, Jingchuan, China \\ ${ }^{2}$ Gansu Province Agricultural Service Center of Luohandong People's Government, Jingchuan, China
}

Email address:

sjb666100@126.com (Shi Shuping)

${ }^{*}$ Corresponding author

\section{To cite this article:}

Shi Jubao, Lei Zongchang, Shi Shuping. Study an Fertilizer Effect of Wheat in Dryland Area of Eastern Gansu Province, China. American Journal of Bioscience and Bioengineering. Vol. 7, No. 3, 2019, pp. 51-56. doi: 10.11648/j.bio.20190703.12

Received: August 16, 2018; Accepted: June 29, 2019; Published: July 16, 2019

\begin{abstract}
The purpose of this study is to investigate the fertilizer and fertilizer use conventional fertilization on wheat production, provide technical basis for the rational use of chemical fertilizers. Using field randomized block experiment, through the formulation N187.5 kg, P90.0 kg, K60.0 kg, N187.59 kg, P90.0 kg, N187.5 kg, K60.0 kg, P90.0 kg, K60.0 N157.5 kg kg and conventional P88.5 kg, K88.5 kg, N157.5 kg, P88.5 kg, N157.5 kg, K88.5 kg, P88.5 kg, K88.5 kg fertilizer rate comparison, the utilization rate of nitrogen, phosphorus and potassium fertilizer materials and the impact on production. Results show that the plastic film mulching cultivation under a $\mathrm{g}$ a, fertilizer than average wheat yield of $537.75 \mathrm{~kg} / \mathrm{hm}^{2}$, increase $7.31 \%$. Fertilizer use efficiency increased by $12.51 \%, 2.4 \%$ (2.4\% nitrogen, phosphate, potash) conclusion: in longdong HanYuan or poor fertility zone production level, the formula ratio N12.5: P6: K4, using plastic film mulching cultivation, soil testing formula fertilization of wheat nitrogen fertilizer utilization rate was $37.4 \%$, the utilization rate of $24.1 \%$ phosphate fertilizer, potash fertilizer utilization rate of $43.0 \%$. Conventional fertilization of wheat nitrogen fertilizer utilization rate is $35.0 \%$, utilization rate of $21.9 \%$ phosphate fertilizer, potash fertilizer utilization rate of $35.1 \%$. Fertilizer compared with conventional fertilization, has significant stimulation effect, can significantly improve the utilization rate of fertilizer application should be promoted.
\end{abstract}

Keywords: Winter Wheat, Fertilizer, Fertilizer Utilization, Production

\section{Introduction}

Winter wheat is the main food crops in longdong region, perennial plant area of $267000 \mathrm{hm} 2$, accounts for $50-55 \%$ of the area sown to grain production level is only $3000 \mathrm{~kg} / \mathrm{hm} 2$ [1]. Over the years, the region farmers blind fertilization according to experience, usually caused by agricultural production field fertilization or partial, and too much abuse phenomenon seriously [2]. Excessive fertilization excess easy create single element fertilizer farmland, poor efficiency of nutrients absorbed by crops, nitrogen, phosphorus, potassium and other chemical consolidation into a salt, make the structure of soil nutrient imbalance, physical property variation [3]. In addition, due to soil nutrient unbalance, easily lead to wheat transformation of nutrients, affect the wheat yield and quality. This not only cause pollution to the ecological environment [4], also increased crop production costs, reduce crop yield and quality, reduce the agricultural income.

In response to the production of wheat fertilization is not standard, reduce fertilizer waste events continue to occur, longdong HanYuan jingchuan county agricultural extension center combining with soil fertility conditions and rules of wheat needs fee, according to the soil itself to protecting fertilizer, fertilizer ability, development and implementation of organic manure and chemical fertilizer, nitrogen fertilizer and under appropriate proportion, to establish a set of suitable for HanYuan of fertilizing the balance of soil science. In 2005 the ministry of agriculture issued by the measured soil fertilizer specification (try out) "' 3414" plan is recommended for the design. This article in the 2012-2015, on the basis of "3414" experiment, through the contrast test of wheat field nitrogen, phosphate and potash, ascertained the HanYuan arid area measured soil fertilizer and wheat under conventional fertilization of nitrogen, phosphate and potash use present situation and the use efficiency, to longdong loess or poor 
fertility HanYuan area, research on wheat fertilization effect under the condition of mulch, provide the basis for guiding field wheat yield.

\section{Test Materials and Methods}

\subsection{Testbed}

Jingchuan county located in the eastern part of gansu province, east longitude $107^{\circ} 15-45^{\prime}$, latitude $35^{\circ} 11-31^{\prime}$ between, is located at longdong loess plateau gully region, with a total area of 1409.3 square kilometers, sea 930-1460 meters, the annual average temperature $10^{\circ} \mathrm{C}$, the county-wide 15 towns and districts. Continuous fixed-point in gansu province in 2012-2015 XuGu Village jingchuan county party completed $23^{\prime} 59^{\prime \prime}$, latitude $35^{\circ}$ east longitude $107^{\circ} 17^{\prime} 46^{\prime \prime}$, at an altitude of $1343 \mathrm{~m}$, average annual rainfall $553 \mathrm{~mm}$, average annual effective accumulated temperature of $3320^{\circ} \mathrm{C}$, frost-free period of $174 \mathrm{~d}$ HanYuan area, for black lu to soil, soil fertility of medium. $16.06 \mathrm{~g} / \mathrm{kg}$ of soil organic matter, total nitrogen, $1.28 \mathrm{~g} / \mathrm{kg}(23.3 \mathrm{mg} / \mathrm{kg}$, effective phosphorus, rapidly-available potassium $208 \mathrm{mg} / \mathrm{kg}, \mathrm{pH} 8.31$, the previous corn crop.

\subsection{Test Materials}

Volunteers of wheat in wheat varieties for 175, the precocious varieties, cold resistance, drought resistance, resistance to lodging, tiller earing rate is high, high and stable yield, is the main varieties of mulch cultivation in arid regions. Selected for urea nitrogen production (inclusive of our $46 \% \mathrm{~N}$ $\geq$, sinopec ningxia branch), phosphate fertilizer for ordinary superphosphate (inclusive of our 12\% P2O5 $\geq$, kunming jinning Jin Hong phosphate fertilizer plant production), potash fertilizer for potash on particles (inclusive of our $30 \% \mathrm{~K} 2 \mathrm{O} \geq$, qinghai golmud kunduz treasure potash co., LTD., production).

\subsection{Test Method}

Split plot design was used, repeated three times, the main treatment for conventional and two formula, vice processing for NPK, PK, NK, NP, a total of four processing. Plot area 20 $\mathrm{m} 2,5 \mathrm{~m}$ long, $4 \mathrm{~m}$ wide. Test fertilizer treatment (table 1).

Table 1. The treatment of different fertilizer on wheat.

\begin{tabular}{|c|c|c|c|c|}
\hline \multirow{2}{*}{\multicolumn{2}{|c|}{ Treatment Major treatment Minor treatment }} & \multicolumn{3}{|c|}{$\left(\mathrm{kg} / \mathrm{hm}^{2}\right)$ Fertilizer amount } \\
\hline & & $\mathbf{N}$ & $\mathbf{P}$ & $\mathbf{K}$ \\
\hline \multirow{4}{*}{ Prescription fertilization } & NPK & 187.5 & 90.0 & 60.0 \\
\hline & NP & 187.5 & 90.0 & 0 \\
\hline & NK & 187.5 & 0 & 60.0 \\
\hline & PK & 0 & 90.0 & 60.0 \\
\hline \multirow{3}{*}{ Conventional fertilizer } & NPK & 157.5 & 88.5 & 88.5 \\
\hline & NK & 157.5 & 0 & 88.5 \\
\hline & PK & 0 & 88.5 & 88.5 \\
\hline
\end{tabular}

Experiment with plastic film mulching cultivation, deep ploughing and before planting break hukki, pick up root crop, 0 to $20 \mathrm{~cm}$ top layer mixed soil sample was taken at the same time. Then district planning, according to the plan calls for draw village, then each handle mu fertilizer, fertilizer rate conversion into a village and converting the village broadcasting the earth's surface, and then to a rotary tillage. And then reset to district planning, and finally coated dibbling machine is adopted to improve the mechanical seeding, $15 \mathrm{~cm}$ row spacing, hole spacing of $13.5 \mathrm{~cm}, 495000$ holes/hm2, each hole 8-12, sowing quantity is $225 \mathrm{~kg} / \mathrm{hm} 2$. After sowing to markup between the village ridge, surrounded by a line protection. Test on October 2, fertilizing soil preparation, planting on October 3rd. On June 30, harvest, and at the same time collecting plant samples and other management measures to different field.

\subsection{Data Collection and Analysis}

This data have adopted the test average of 3 years, wheat seeding from 2012 to 2012 the result of the wheat harvest, points in analyzing the grain and $\mathrm{N}, \mathrm{P}, \mathrm{K}$ content in the stem, gathering top layer of soil $(0 \sim 20 \mathrm{~cm})$ analysis of soil organic matter, total $\mathrm{N}$ and inorganic $\mathrm{N}$, valid $\mathrm{P}$, valid $\mathrm{K}$.

Before winter, uniform emergence and growing strong in the village of edge line areas selected two $1 \mathrm{~m}$ sample period, investigating the basic seedling. Spring before jointing stage survey sample period of maximum tillering; Determination of sample after flowering period of panicle number and converted into panicles per unit area. Mature period in the three points were randomly selected in the district, the measuring plant height, calculate the average plant height; In the edge line section randomly selected 20 spike, number of spike grain number, reduced grain number per panicle, recorded in the field emergence and heading stage and mature stage. Village after harvest hang dry to water content is $13 \%$ when weighing, measuring grain, converted into hectare plot the total weight gain. Calculate yield rate ratio, agronomy, soil, fertilizer rate, fertilizer utilization efficiency, etc. [6]. Using SAS9.3 software factors variance analysis to yield and its composition, using EXCEL by regression analysis.

\section{Test Results and Analysis}

\subsection{The Effect of Fertilizer Treatment on Yield and Benefit Analysis}

According to the test results summary fertilizer NPK area 
average yield of $7895.3 \mathrm{~kg} / \mathrm{hm} 2$, than $\mathrm{K}$ area average yield of $6863.4 \mathrm{~kg} / \mathrm{hm} 2$ increase $1031.9 \mathrm{~kg} / \mathrm{hm} 2$, than no $\mathrm{P}$ area average yields $6163.4 \mathrm{~kg} / \mathrm{hm} 2,1731.9 \mathrm{~kg} / \mathrm{hm} 2$, than no $\mathrm{N}$ area average yield of $5560.1 \mathrm{~kg} / \mathrm{hm} 2,2325.2 \mathrm{~kg} / \mathrm{hm} 2$ to increase production. Conventional fertilizer NPK area average yield of 7357.4 $\mathrm{kg} / \mathrm{hm} 2$, than $\mathrm{K}$ area average yield of $6116.7 \mathrm{~kg} / \mathrm{hm} 2$, increase of $1240.7 \mathrm{~kg} / \mathrm{hm} 2$, than no $\mathrm{P}$ area average yield of 5808.3 $\mathrm{kg} / \mathrm{hm} 2$, increase of $1549.1 \mathrm{~kg} / \mathrm{hm} 2$, than no $\mathrm{N}$ area average yield of $5521.7 \mathrm{~kg} / \mathrm{hm} 2,1835.7 \mathrm{~kg} / \mathrm{hm} 2$ to increase production. Compared to the conventional fertilizer NPK fertilizer NPK area area increase $501.9 \mathrm{~kg} / \mathrm{hm} 2$, without $\mathrm{K}$ area than conventional fertilization of applying fertilizer $\mathrm{K}$ area increase $748.7 \mathrm{~kg} / \mathrm{hm} 2$, without $\mathrm{P}$ area than conventional fertilization of applying fertilizer $\mathrm{P}$ area increase $357.1 \mathrm{~kg} / \mathrm{hm} 2$, formula fertilization without $\mathrm{N}$ area than conventional fertilizer $\mathrm{N}$ area $38.4 \mathrm{~kg} / \mathrm{hm} 2$ to increase production. (table 2).

Analysis of variance was applied to test the significance of determination of formula fertilization between the area $\mathrm{F}=$ 29.51, > F0.05 = 4.76, 4.76 and F0.01 reached extremely significant level. $\mathrm{F}=49.50$, between conventional fertilization area processing $>\mathrm{F} 0.05=4.76,4.76$ and F0.01 also reached significant level (table 3 ).

See from table 3, no significant difference between the experimental group, the main processing and processing the yield difference between extremely significant. Therefore, fertilizer and conventional fertilization exist significant differences, different fertilizer treatments on each plot yield also has a significant impact.

Table 2. Wheat fertilizer efficiency test yield summary table unit: $\mathrm{hm}^{2}, \mathrm{~g}, \mathrm{~kg}$.

\begin{tabular}{|c|c|c|c|c|c|c|c|c|c|}
\hline \multirow{2}{*}{\multicolumn{2}{|c|}{ Test processing }} & \multicolumn{8}{|c|}{ Test the annual } \\
\hline & & \multicolumn{4}{|c|}{ In 2012-2013 } & \multicolumn{4}{|c|}{ In 2013-2014 } \\
\hline $\begin{array}{l}\text { The main } \\
\text { processing }\end{array}$ & $\begin{array}{l}\text { Deputy } \\
\text { processing }\end{array}$ & $\begin{array}{l}\mathbf{h m}^{2} \\
\text { ears }\end{array}$ & $\begin{array}{l}\text { Spike grain } \\
\text { number }\end{array}$ & grain & $\begin{array}{l}\mathrm{hm}^{2} \\
\text { production }\end{array}$ & $/ \mathbf{h m}^{2}$ ears & $\begin{array}{l}\text { Spike grain } \\
\text { number }\end{array}$ & $\begin{array}{l}\text { thousand } \\
\text { kerner weight }\end{array}$ & $\begin{array}{l}\mathrm{hm}^{2} \\
\text { production }\end{array}$ \\
\hline \multirow{4}{*}{$\begin{array}{l}\text { The area of } \\
\text { applying } \\
\text { fertilizer }\end{array}$} & NPK & 782.0 & 29.4 & 40.1 & 7758.0 & 788.0 & 28.9 & 40.2 & 7869.0 \\
\hline & NP & 740.4 & 27.4 & 38.8 & 6694.5 & 774.5 & 26.2 & 39.8 & 6892.5 \\
\hline & NK & 748.1 & 24.5 & 38.4 & 6088.5 & 727.8 & 25.1 & 38.9 & 6147.0 \\
\hline & $\mathrm{PK}$ & 708.8 & 23.9 & 38.1 & 5482.5 & 718.1 & 23.5 & 38.3 & 5503.5 \\
\hline \multirow{4}{*}{$\begin{array}{l}\text { Conventional } \\
\text { fertilization area }\end{array}$} & NPK & 732.6 & 28.7 & 40.2 & 7233.0 & 778.1 & 28.1 & 39.9 & 7342.5 \\
\hline & NP & 709.8 & 25.4 & 39.6 & 6063.0 & 740.1 & 23.5 & 40.8 & 6042.0 \\
\hline & NK & 732.6 & 22.8 & 39.8 & 5724.0 & 764.3 & 22.9 & 39.4 & 5817.0 \\
\hline & PK & 706.7 & 22.6 & 39.5 & 5449.5 & 735.5 & 21.7 & 40.4 & 5485.5 \\
\hline
\end{tabular}

Table 2. Continued.

\begin{tabular}{|c|c|c|c|c|c|c|c|c|c|}
\hline \multirow{2}{*}{\multicolumn{2}{|c|}{ Test processing }} & \multicolumn{4}{|c|}{ Test the annual } & \multirow{2}{*}{\multicolumn{4}{|c|}{ Three years on average }} \\
\hline & & In 2014-20 & & & & & & & \\
\hline $\begin{array}{l}\text { The main } \\
\text { processing }\end{array}$ & $\begin{array}{l}\text { Deputy } \\
\text { processing }\end{array}$ & $/ h^{2}$ ears & $\begin{array}{l}\text { Spike grain } \\
\text { number }\end{array}$ & grain & $\begin{array}{l}/ \mathrm{hm}^{2} \\
\text { production }\end{array}$ & $\begin{array}{l}\text { spike number } \\
/ \mathrm{hm}^{2} \text { ears }\end{array}$ & $\begin{array}{l}\text { Spike grain } \\
\text { number }\end{array}$ & grain & $\begin{array}{l}/ \mathrm{hm}^{2} \\
\text { production }\end{array}$ \\
\hline \multirow{3}{*}{$\begin{array}{l}\text { The area of } \\
\text { applying } \\
\text { fertilizer }\end{array}$} & NPK & 785.7 & 30.1 & 40.5 & 8058.0 & 785.4 & 29.80 & 40.28 & 7895.3 \\
\hline & NP & 777.8 & 26.8 & 39.1 & 7003.5 & 774.2 & 26.00 & 39.89 & 6863.4 \\
\hline & NK & 754.7 & 25.3 & 39.0 & 6253.5 & 736.7 & 24.70 & 38.94 & 6163.4 \\
\hline \multirow{4}{*}{$\begin{array}{l}\text { Conventional } \\
\text { fertilization area }\end{array}$} & NPK & 766.8 & 28.2 & 40.6 & 7497.0 & 761.7 & 28.20 & 40.46 & 7357.4 \\
\hline & NP & 735.9 & 24.1 & 41.7 & 6244.5 & 735.2 & 23.73 & 40.70 & 6116.7 \\
\hline & NK & 729.6 & 23.3 & 40.2 & 5884.5 & 747.1 & 22.97 & 39.82 & 5808.3 \\
\hline & PK & 728.1 & 22.4 & 40.5 & 5629.5 & 723.6 & 22.07 & 40.13 & 5521.7 \\
\hline
\end{tabular}

Table 3. Variance analysis for different fertilizer treatment.

\begin{tabular}{lllll}
\hline Variation resource & df & SS & MS & F \\
\hline Repetition & 4 & 1839.4 & 459.8 & 0.275 \\
Main treatment & 1 & 4691.3 & 4691.3 & 1.5 \\
NPK、NP、NK、 PK) Minor treatment & 3 & 64559.3 & 1519.8 & 0.002 \\
Interaction & 3 & 1803.1 & 601.0 & 0 \\
Error & 12 & 3781.9 & 315.2 & 1.9 \\
Total variation & 23 & 76675 & & \\
\hline
\end{tabular}

Table 4. Analysis of yield and profit among different treatment unit: $\mathrm{kg} / \mathrm{hm}^{2}$.

\begin{tabular}{lllll}
\hline To deal with & NPK & PK & NK & NP \\
\hline Conventional fertilizer & $7357.4 \mathrm{a}$ & $5521.7 \mathrm{~d}$ & $5808.3 \mathrm{c}$ \\
Prescription fertilization & $7895.3 \mathrm{a}$ & $5560.1 \mathrm{~d}$ & $6163.4 \mathrm{c}$ & 6.1 \\
Yield increase rate & 7.3 & 0.7 & $6863.4 \mathrm{~b}$ & 12.2 \\
Increased profit & 9.4 & 3.1 & 8.2 & 12.4 \\
\hline
\end{tabular}


Test results show that the fertilizer NPK area than K area increase by $15.0 \%$, increasing $26.1 \%$, than without $\mathrm{P}$ area production $28.1 \%$ income $28.1 \%$, yield increased by $42.0 \%$, than no $\mathrm{N}$ area increase by $40.3 \%$. Yield was $20.3 \%$ higher than that of the conventional fertilizer NPK area than K area, a new $15.8 \%$; Yield increased by $26.7 \%$, increase $23.6 \%$ than $P$ area; The yield increased by $26.7 \%$, increasing $32.3 \%$ than $\mathrm{N}$ area. Compared to the conventional fertilizer NPK fertilizer NPK zone area, the yield increased by $7.3 \%$, the average income $9.4 \%$; No $\mathrm{K}$ fertilizer area than conventional fertilization without $\mathrm{K}$ area increase $12.2 \%, 12.4 \%$ increase; Formula fertilization without $\mathrm{P}$ area than conventional fertilization $\mathrm{P}$ area increase $6.1 \%, 8.2 \%$ increase; Formula fertilization without $\mathrm{N}$ area than conventional fertilization yield increased by $0.7 \%$, increase $3.1 \% \mathrm{~N}$ area (table 4 ). Formula fertilization increase production effect is significantly higher than that of conventional fertilization, fertilizer NPK area is the highest yield, regular NPK fertilizer production times, followed by fertilizer NP area, conventional fertilizer NP area, fertilizer NK area, conventional fertilizer NK area, fertilizer PK, conventional fertilizer PK area yield the lowest.

\subsection{The Fertilizer Treatment on the Influence of Growth Period}

Look from the stages of investigation, test the processing growth period had no obvious effect on it. Whether the area of applying fertilizer or conventional fertilization area, various processing stages, only slightly different without $\mathrm{N}$ and $\mathrm{P}$ area, including formula fertilization area, with no $\mathrm{N}$ tillering delayed 1 day, green period delay 1-2 days, jointing stage delayed 1-2 days, heading stage 2-3 days, Yang flowering, grouting period were delayed 1-2 days, 2-3 days early maturity. Tillering stage delayed 0 and 1 day without $\mathrm{P}$ area, green stage, jointing stage delayed 1 day, heading stage, Yang flowering delay 1-2 days, grouting time delay 1 day, 1 to 2 days early maturity. Conventional fertilization area, with no $\mathrm{N}$ tillering stage, green returned stage delayed 1-2 days, jointing stage 1 day delay, heading stage was delayed by 2 to 3 days, Yang flowering, grouting period were delayed 1-2 days, 2-3 days early maturity. Tillering stage delayed 0 and 1 day without $\mathrm{P}$ area, green stage, jointing stage, heading stage, Yang flowering delay 1-2 days, grouting time delay 1 day, 1-2 days early maturity (table 5).

See from table 5, without $\mathrm{N}$ and $\mathrm{P}$ area the whole growth period than other area, root, jointing, earing, those of tillers, grouting time delay 1-3 days, 1-2 days early maturity, in longdong dry The original or poor N P K deficiency less enough fertility zone, $\mathrm{N}$ fertilizer and $\mathrm{P}$ fertilizer had a greater influence on the production of wheat, and $\mathrm{K}$ fertilizer soil content enough, had a little effects on wheat production, try to consider formula NPK fertilizer on fertilizer use.

Table 5. The effect of different fertilizer on growth period.

\begin{tabular}{|c|c|c|c|c|c|c|c|c|c|}
\hline & \multicolumn{3}{|c|}{ Green period } & \multicolumn{3}{|c|}{ Jointing stage } & \multicolumn{3}{|c|}{ Heading stage } \\
\hline & 2013 & 2014 & 2015 & 2013 & 2014 & 2015 & 2013 & 2014 & 2015 \\
\hline NPK & $11 / 3$ & $13 / 3$ & $12 / 3$ & $11 / 4$ & $10 / 4$ & $9 / 4$ & $8 / 5$ & $9 / 5$ & $8 / 5$ \\
\hline NP & $12 / 3$ & $13 / 3$ & $12 / 3$ & $10 / 4$ & $12 / 4$ & $9 / 4$ & $7 / 5$ & $9 / 5$ & $8 / 5$ \\
\hline NK & $12 / 3$ & $14 / 3$ & $13 / 3$ & $12 / 4$ & $13 / 4$ & $10 / 4$ & $9 / 5$ & $10 / 5$ & $8 / 5$ \\
\hline PK & $13 / 3$ & $14 / 3$ & $13 / 3$ & $12 / 4$ & $12 / 4$ & $10 / 4$ & $10 / 5$ & $11 / 5$ & $9 / 5$ \\
\hline
\end{tabular}

Table 5. Continued.

\begin{tabular}{|c|c|c|c|c|c|c|c|c|c|}
\hline & \multicolumn{3}{|c|}{ Yang flowering } & \multicolumn{3}{|c|}{ Filling stage } & \multicolumn{3}{|c|}{ The mature stage } \\
\hline & 2013 & 2014 & 2015 & 2013 & 2014 & 2015 & 2013 & 2014 & 2015 \\
\hline NPK & $17 / 5$ & $17 / 5$ & $15 / 5$ & $29 / 5$ & $29 / 5$ & $26 / 5$ & $23 / 6$ & $21 / 6$ & $22 / 6$ \\
\hline NK & $18 / 5$ & $18 / 5$ & $17 / 5$ & $29 / 5$ & $30 / 5$ & $27 / 5$ & $22 / 6$ & $21 / 6$ & $21 / 6$ \\
\hline PK & $18 / 5$ & $19 / 5$ & $17 / 5$ & $30 / 5$ & $31 / 5$ & $28 / 5$ & $20 / 6$ & $19 / 6$ & $20 / 6$ \\
\hline
\end{tabular}

\subsection{The Fertilizer Treatment on the Influence of the Economic Characters of Wheat}

Different fertilizer treatment on has a great influence on its economic characters. Except for the tiller, plant height, ear length difference was not significant, the area of applying fertilizer, NPK area enough into the production of the three elements, panicle number and grain number and grain than $\mathrm{K}$ (NP) an increase of $112000 / \mathrm{hm} 2,3.8,1.4 \mathrm{~g}$ of grains; Growth of $1.6 \%, 14.6 \%$ and $1.6 \%$ respectively. Than no $\mathrm{P}$ (NK), an increase of $33000 / \mathrm{hm} 2,5.1,1.3 \mathrm{~g}$ of grains; Growth of $11.5 \%, 4.9 \%$, and $11.5 \%$ respectively. Than $\mathrm{N}$ (PK), an increase of $570000 / \mathrm{hm} 2,6.6,2.1 \mathrm{~g}$ of grains;
Growth of $2.7 \%, 28.5 \%$ and $2.7 \%$ respectively. Conventional fertilization area, NPK OuDeSui number, spike grain number, grain, than K (NP) number of ears and grains, and grains increased $15000 / \mathrm{hm} 2,4.5$ and $0.24 \mathrm{~g}$ of grains and growth of $3.6 \%, 3.6 \%$ and $0.6 \%$ respectively. Than $\mathrm{P}(\mathrm{NK})$ ear Numbers per spike, grain number, increase 10000 ears/hm2, respectively 5.2 and $0.6 \mathrm{~g}$, growth of $2.0 \%, 22.6 \%$ and $2.0 \%$ respectively. Than $\mathrm{N}$ (PK) ear Numbers per spike, grain number, increase 375000 ears/hm2, respectively 6.1 and $0.3 \mathrm{~g}$, an increase of $5.3 \%, 27.6 \%$ and $0.8 \%$. (table 6 ).

The results showed that the fertilizer in the total number of stem, spike grain number per spike and significantly improved; Besides NK processing hm2 panicles also increase; There was 
no significant difference between plant height and spike length. NPK area panicles, spike grain number, grain growth of $2.3 \%, 2.3 \%$ and $0.4 \%$, respectively. With no K ear Numbers per spike, spike grain number, growth of $0.4 \%, 0.4 \%$ and $2.0 \%$ respectively. With no $\mathrm{P}$ ear Numbers per spike, spike grain number, growth of $0.4 \%, 0.4 \%$ and $2.2 \%$ respectively. With no $\mathrm{N}$ number of ears, grain Numbers per spike, the growth of $1.9 \%, 1.9 \%$ and $4.8 \%$ respectively.

Table 6. The effect of fertilizer on wheat economic traits.

\begin{tabular}{|c|c|c|c|c|c|c|c|}
\hline Main Treat & Deputy treat & Total number of stem & Plant height & Ear length & $h^{2}$ ears & Spike grain number & Grain weightg \\
\hline \multirow{4}{*}{ conventional } & NK & $1362 \mathrm{c}$ & $88.7 \mathrm{a}$ & $6.1 \mathrm{~b}$ & $747 \mathrm{ab}$ & $23.0 \mathrm{c}$ & $39.8 b$ \\
\hline & NP & $1438 b$ & $89.7 \mathrm{a}$ & $6.3 \mathrm{a}$ & $735 \mathrm{bc}$ & $23.7 b$ & $40.7 \mathrm{a}$ \\
\hline & NPK & $1492 \mathrm{a}$ & $88.3 \mathrm{a}$ & $6.2 \mathrm{a}$ & $762 \mathrm{a}$ & $28.2 \mathrm{a}$ & $40.5 \mathrm{a}$ \\
\hline & PK & $1312 d$ & $86.3 b$ & $5.7 \mathrm{c}$ & $723 c$ & $22.1 \mathrm{~d}$ & $40.1 \mathrm{~b}$ \\
\hline \multirow{3}{*}{ formula } & NK & $1422 \mathrm{c}$ & $89.0 \mathrm{a}$ & $6.1 \mathrm{~b}$ & $736.5 \mathrm{bc}$ & $24.7 \mathrm{c}$ & $38.9 b$ \\
\hline & NP & $1545 b$ & $90.0 \mathrm{a}$ & $6.3 \mathrm{a}$ & $769.5 \mathrm{ab}$ & $26.0 \mathrm{~b}$ & $39.9 \mathrm{a}$ \\
\hline & PK & $1375 d$ & $88.0 \mathrm{~b}$ & $5.9 \mathrm{c}$ & $729 c$ & $23.2 \mathrm{~d}$ & $38.2 b$ \\
\hline \multicolumn{2}{|c|}{ significance between main treat } & $* *$ & ns & ns & $*$ & $* *$ & $* *$ \\
\hline
\end{tabular}

Table 7. The evaluation of fertilizer efficiency in different treat.

\begin{tabular}{|c|c|c|c|c|c|c|}
\hline \multirow[b]{2}{*}{ Main treat } & \multirow[b]{2}{*}{ Fertilizer types } & \multicolumn{5}{|c|}{ Fertilizer efficiency evaluation index } \\
\hline & & $\begin{array}{l}\text { Increase rate of grain } \\
\text { yield }\end{array}$ & $\begin{array}{l}\text { Fertilizer } \\
\text { contribution }\end{array}$ & Soil contribution & $\begin{array}{l}\text { Agriculture } \\
\text { Efficiency }\end{array}$ & $\begin{array}{l}\text { Fertilizer use } \\
\text { efficiency }\end{array}$ \\
\hline \multirow{3}{*}{ conventional } & $\mathrm{N}$ & 33.3 & 25.0 & 75.0 & 11.7 & 35.0 \\
\hline & $\mathrm{P}$ & 26.7 & 21.1 & 78.9 & 17.5 & 21.9 \\
\hline & $\mathrm{K}$ & 20.3 & 16.9 & 83.1 & 14.0 & 35.1 \\
\hline \multirow{2}{*}{ formula } & $\mathrm{N}$ & 42.0 & 29.6 & 70.4 & 12.5 & 37.4 \\
\hline & $\mathrm{K}$ & 15.0 & 13.1 & 86.9 & 17.2 & 43.0 \\
\hline
\end{tabular}

1) Current in longdong area HanYuan barren fertility level of the production, the plastic film mulching cultivation, soil testing formula fertilization of wheat nitrogen fertilizer utilization rate was $37.4 \%$, the utilization rate of $24.1 \%$ phosphate fertilizer, potash fertilizer utilization rate of $43.0 \%$. Conventional fertilization of wheat nitrogen fertilizer utilization rate is $35.0 \%$, utilization rate of $21.9 \%$ phosphate fertilizer, potash fertilizer utilization rate of $35.1 \%$. Compared with conventional fertilization formula fertilization, has significant stimulation effect, can significantly improve the fertilizer utilization ratio. Formula fertilization conditions, the residues of fertilizer in the soil and low loss, large amounts of fertilizer residue and loss occurs mainly in unreasonable high conventional fertilization conditions, therefore, to prevent excessive fertilization is currently under the condition of high yield and fertilizer management at the core of the problem [7], the test results show that the formula fertilization than conventional fertilization of wheat an average increase of $537.8 \mathrm{~kg} / \mathrm{hm} 2$, increase $7.3 \%$. Fertilizer use efficiency increased by $12.5 \%$, of which the nitrogen use efficiency increased by $2.4 \%$, utilization rate increase $2.2 \%$ phosphate fertilizer, potash fertilizer utilization ratio increased by $7.9 \%$.

2) On the basis of NPK fertilizer rate, through the regression calculation, it is concluded that the regression equation of the fertilizer rate and yield, grain yield $=\mathrm{P}+$ $\mathrm{N}+2944.3+6.4 * 2944.3 * 27.4 * \mathrm{~K}$. Therefore the current level of fertilization, in the output of the unit of fertilizer and potash fertilizer is highest, lowest nitrogen fertilizer. However, the current level of the fertilizer, the yield rate of $\mathrm{N}$ element, fertilizer contribution rate, the highest utilization rate of fertilizer, the corresponding contribution rate of soil and agronomic efficiency of minimum; P element of production rate and contribution rate, soil fertilizer contribution of medium, agronomy, most efficient and lowest fertilizer use efficiency; The increase rate of $\mathrm{K}$ element minimum ratio, agriculture, fertilizer efficiency, the largest contribution rate of soil and fertilizer use efficiency. The European KNS (kulturbegleitende Nmin - Sollwertesystem) fertilizer recommendation approach is based on the soil inorganic nitrogen $(\mathrm{Nmin}=\mathrm{N} 4$ interchange $++\mathrm{NO} 3--\mathrm{N}=\mathrm{N})$ measured on the basis of considering the growth of the crop nutrient absorption [8]. China agricultural university in the dryland wheat in the north of China using Nmin nitrogen fertilizer recommendation preliminary success [9]. Farmland fertilizer consumption is growing rapidly in our country, generally with the increasing of application rate of nitrogen, nitrogen utilization rate dropped significantly, and the nitrogen fertilizer utilization rate and loss rate and soil residual rate has a tendency to rise. Ju xiaotang study nitrogen in winter wheat crop rotation system to found after one season crop growth is still $20.9 \% 48.4 \%$ nitrogen fertilizer residues in the $0-100 \mathrm{~cm}$ soil layer, the remaining after the fertilizer for crop use [10], so when making fertilizer, fertilizer should be comprehensive consideration of potential yield and fertilizer use efficiency, maximize the fertilizer efficiency. 


\section{Conclusion}

Wheat soil testing formula fertilization is according to the laws of the crop fertilizer, soil fertilizer and fertilizer production performance effect, on the premise of organic fertilizer on the basis of, put forward the suitable dosage of nitrogen, phosphorus and potassium fertilizer material and proportion and corresponding fertilization technology methods of fertilizer application. In longdong HanYuan mulch cultivation conditions or poor fertility area, should be vigorously popularizing the technology of applying fertilizer. Per hectare nitrogen, $187.5 \mathrm{~kg}$, $90 \mathrm{~kg}$ of $\mathrm{p}$, $\mathrm{k}$ of $60 \mathrm{~kg}$ fertilizer levels suitable for high current fertile plot the actual production of wheat, should be vigorously promoted.

\section{Acknowledgements}

This paper bearing the Chinese academy of agricultural sciences institute of crop science, gansu province academy of agricultural sciences' dry farming xing-mao li researcher Dr Yong-gui xiao guidance, we would like to thank the table.

\section{Fund Project}

The column measured soil fertilizer subsidies project (GanCai agriculture [77] 2008).

\section{References}

[1] Shi Jubao Liu Pengzhong, wheat in 175 in gansu province east HanYuan (3) the yield potential analysis J, crops, 2015 (2); 178-178.
[2] FuYunZhang NieLongXing He Xiaobin Zhang, wenshan upland soil nutrient abundance of chili red soil and fertilization index system research, China's agricultural technology, 2015. $11 ; 30-33$.

[3] Zhang jing, Cheng Yuan, etc., analyses the determination of the organic matter content in the fertilizer and influencing factors of J, China to extension 2015 (12), 44-46.

[4] Z-sen, J crop nutrition and fertilizer, crop nutrition and fertilizer journal 2006. 12 (4); 473-473.

[5] FuYunZhang NieLongXing He Xiaobin Zhang, wenshan upland soil nutrient abundance of chili red soil and fertilization index system research J, agricultural technology in China, 2015. $11 ; 30-33$.

[6] Soloing, crop fertilizer technical manual M, culture of science and technology press, 2006; First edition: 713.

[7] And chuan-long he spring cabbage - corn - winter cabbage nitrogen under 2-year study J, China's agricultural science, 2007. 40 (11); 2527-2527.

[8] Liao Xiaoyong, soil nitrogen behavior in the farmland ecosystem research status and prospect of $\mathrm{J}$, journal of southwest agricultural, 2001, 14 (3); 94-98.

[9] Ju xiaotang, etc., on the outskirts of Beijing nitrogen in winter wheat/summer maize rotation system to study J, journal of plant nutrition and fertilizer, 2003, 9 (3); 264-270.

[10] Theory of jun-min zhang, sand ginger, black soil productive potential and comprehensive governance. See: jun-min zhang. Sand ginger black soil comprehensive governance study. M, hefei in anhui science and technology publishing house, 1988-2-11. 